\title{
A MÁQUINA DE JOSEPH WALSER: INDIFERENÇA E TOTALITARISMO
}

\author{
Maria Isabel Bordini ${ }^{1}$
}

Resumo: $O$ presente artigo faz uma análise da figuração da guerra no romance $A$ máquina de Joseph Walser, do escritor português Gonçalo M. Tavares. A guerra é apresentada como momento em que se evidencia a relação entre uma postura individual de isolamento e indiferença e a perpetração coletiva das formas mais radicais de violência: aquelas engendradas pelo domínio totalitário. A ligação entre indiferença e totalitarismo encontra-se iconizada, segundo nossa leitura, na relação destrutiva que os personagens Klober Muller e Joseph Walser desenvolvem entre si. A indiferença que ambos manifestam, decorrente do atrofiamento da consciência e da capacidade de julgar, é a contraface da violência exercida em moldes totalitários.

Palavras-chave: guerra, totalitarismo, indiferença

Abstract: This paper analyses the representation of war in the novel $A$ máquina de Joseph Walser, by portuguese writer Gonçalo M. Tavares. In this novel war is a moment in which there is a relation between individual attitude of isolation and indifference and collective radical violence: the totalitarianism. The connection between indifference and totalitarianism is pictured in the destructive relationship kept by the characters Klober Muller and Joseph Walser. Both show indifference, which results from the shrinkage of conscious and judgment and is the counterpart of totalitarian violence.

Keywords: war, totalitarianism, indifference

\footnotetext{
${ }^{1}$ Doutorado em andamento em Estudos Literários, na Universidade Federal de Minas Gerais. E-mail: belbordini@gmail.com
} 
O romance $A$ máquina de Joseph Walser é o segundo de uma tetralogia denominada $O$ Reino, do escritor português contemporâneo Gonçalo M. Tavares. Trata-se de uma série de quatro romances ${ }^{2}$ articulados não por uma linha de continuidade entre os enredos, que podem ser lidos de maneira independente uns dos outros, mas pelos temas, pelos cenários e pelas circunstâncias que as histórias apresentam em comum. As quatro narrativas se passam em uma mesma cidade não nomeada que sofre com a guerra. Há, portanto, um conflito armado que está ou em desenvolvimento, ou em vias de acontecer, ou recém terminado em cada um dos romances. Tem-se a indicação de que se trata da mesma guerra que atravessa os quatro livros, uma vez que os enredos estão sutilmente interligados por meio de personagens e/ou elementos que fazem breves aparições (pequenas "pontas", por assim dizer) de um livro para outro ${ }^{3}$.

A guerra é, desse modo, um eixo temático que atravessa as quatro narrativas e thes confere certa unidade. Entretanto, em cada um dos romances a guerra ocupa espaço diferenciado e recebe tratamento diverso. Ela constitui em todos eles, porém, um elemento-chave a partir do qual se desenvolvem as relações humanas aí retratadas. Ou seja, a guerra é um dado inolvidável para a análise dessas relações e, em alguns momentos, chega a ser mesmo o motor mais direto de muitas das ações dos personagens. No presente artigo procuraremos delinear possíveis significados para a guerra representada no segundo dos romances de $O$ Reino.

Algumas considerações sobre a tetralogia $O$ Reino se fazem necessárias, à guisa de introdução. A política - entendida aqui, amplamente, como a dimensão da condição humana que corresponde à organização e à gestão da existência dos indivíduos em comunidade - é um dos principais temas de cuja figuração se encarrega a obra $O$ Reino. E particularmente a política em seus momentos de crise. Sendo assim, a recriação literária dos

\footnotetext{
${ }^{2}$ Os títulos que compõem a tetralogia são: Um homem: Klaus Klump; $A$ máquina de Joseph Walser; Jerusalém e Aprender a rezar na era da técnica.

${ }^{3}$ Por exemplo, o protagonista e personagem-título de $A$ máquina de Joseph Walser aparece momentaneamente em Aprender a rezar na era da técnica: é um paciente que causa tumulto no hospital onde Lenz Buchmann, protagonista de Aprender a rezar, trabalha. Joseph Walser tem o dedo indicador direito amputado em decorrência de um acidente de trabalho - acidente que marcará sua trajetória de forma definitiva - e o médico Lenz Buchmann o repreende friamente pelo seu descontrole emocional, desdenhando-o em seguida: "Que importância tem um dedo? Um cobarde, pensou." Tavares, 2008, p. 50.
} 
temas da guerra, da violência e do Estado totalitário desempenha papel fundamental na dinâmica das relações humanas que são representadas nos romances em questão. Alguns dos elementos fundamentais nas dinâmicas sociais figuradas são: a centralidade do trabalho no quadro das relações sociais (do trabalho desenvolvido no espaço industrial, principalmente); a centralidade da ciência e da técnica na compreensão e na organização das vidas individuais (iconizada nas trajetórias dos personagens Theodor Busbeck e Lenz Buchmann, protagonistas, respectivamente do terceiro e quarto romances da série); e a tensão estabelecida no cerne das instituições políticas por conta de uma crise de autoridade. A leitura da representação literária desses temas pode, a nosso ver, ser colocada em diálogo com a leitura de determinados dados da experiência humana historicamente localizados, quais sejam: os movimentos e Estados totalitários e os genocídios levados a cabo em campos de concentração e de extermínio.

Dentro desse quadro de referências históricas, as experiências do nazismo e do Holocausto podem ser evocadas na leitura de $O$ Reino por conta de elementos presentes nas próprias narrativas, mais explicitamente no romance Jerusalém, o terceiro da série, mas que ecoam nos demais romances. Desse modo, ainda que os episódios e personagens construídos não promovam a ligação direta e exclusiva com algum episódio histórico real, permitem realizar um diálogo com uma variedade de experiências humanas, pois a obra de Tavares se trata de uma literatura que parece ao mesmo tempo exigir e negar a possibilidade de contextualização. Isto é, de uma literatura que pretende se constituir como uma voz construtora do mundo, porém, ao mesmo tempo, almeja ser significativa ao maior número possível de situações humanas. Os romances de $O$ Reino parecem ter a preocupação de manter à vista (e em vista), como um pano de fundo histórico e extra-textual visível, alguns dos acontecimentos mais impactantes da história recente, enquanto dados incontornáveis da experiência humana que não podem ser ignorados pelo fazer literário contemporâneo ${ }^{4}$. Nesse sentido, a análise da figuração da

\footnotetext{
${ }^{4}$ A responsabilidade por manter viva uma certa consciência histórica a respeito desses acontecimentos é defendida pelo próprio Gonçalo Tavares, em entrevista ao jornal O Estado de S. Paulo, nos seguintes termos: "A geração que hoje tem 20 anos tem uma relação distante
} 
guerra nesses romances deve levar em conta essa exigência de diálogo com a realidade histórica presente na tetralogia de Gonçalo Tavares.

Partiremos, agora, para o comentário mais específico acerca da figuração da guerra. No primeiro romance da série, Um homem: Klaus Klump, a guerra encontra um tratamento ambivalente, sendo simultaneamente tomada como fenômeno da natureza, que foge ao controle da vontade e da razão, e como fenômeno histórico e especificamente humano, que manifesta a capacidade humana de inovar e modificar a natureza. O romance se estrutura em torno da trajetória do personagem central, Klaus Klump, o qual se envolve diretamente no conflito armado e sobre cuja existência a guerra tem um impacto revolucionário. A máquina de Joseph Walser, por sua vez, em contraste com a narrativa anterior, tematiza o afastamento e a indiferença dos personagens em meio à guerra. A ação narrada acompanha principalmente a perspectiva de Joseph Walser, empregado que ocupa uma colocação inferior (é um trabalhador de base) numa das fábricas de Leo Vast, o rico industrial que já aparecera no romance anterior, para quem a guerra trouxe ganhos econômicos e que, por conta disso, se decepciona com o seu fim.

Walser é um homem estranho, que fala pouco e se veste de um modo desleixado, antiquado. A sua postura de alheamento geral só desaparece quando está a operar com a "sua máquina" na fábrica. Trata-se de uma máquina tão perigosa, que inclusive já havia matado num acidente um trabalhador anterior a Walser, que a este último só resta dedicar-se à máquina como se enfrentasse um inimigo de guerra, isto é, com uma atenção sem brechas. Percebe-se, desse modo, que a dinâmica da guerra é trazida aqui para o próprio ambiente de trabalho. Assim, se no primeiro romance de $O$ Reino a guerra é retratada de forma mais direta e figurativa, aqui ela deixa de ser apenas um elemento externo e se torna algo que impregna todas as relações sociais, a começar pelas relações de trabalho.

com a tragédia [do Holocausto]. Acredito que nossa responsabilidade, como jornalistas e escritores, é fazer com que as pessoas não esqueçam dessa tragédia." FILHO, Antonio Gonçalves. Jerusalém e a presença do mal. O Estado de S. Paulo. São Paulo, 17 de setembro de 2006, Caderno Cultura, p. D11. 
Quanto ao conflito que se desenrola no romance anterior, neste segundo romance temos poucas notícias diretas do seu desenvolvimento, uma vez que Walser decide se manter afastado dos acontecimentos o máximo possível. Contudo, a tensão decorrente do conflito armado não desaparece e, na verdade, há uma tensão presente na atividade de Walser com sua máquina, bem como na sua atitude como um todo, que se coaduna perfeitamente com a tensão decorrente da guerra. A primeira menção à aproximação da guerra se dá nos seguintes termos:

No mundo tranquilo a introdução de uma única substância altera fortemente as previsões para o dia seguinte. A morte ainda não foi introduzida como substância vulgar, mas aproxima-se um mês imundo, segundo algumas previsões.

- Um mês imundo - murmura Walser para a sua mulher Margha.

Mas um mês onde se toca, colocando o medo insultuoso na extremidade dos dedos.

Tocarás no próximo mês como tocas com a mão direita no rio sujo: depois deverás limpar os dedos, lavá-los. (TAVARES, 2010, p. 10)

Conforme está indicado, Walser toma consciência da proximidade do conflito e percebe-o como algo com o qual não se deve envolver em demasiado (depois de tocá-lo com os dedos deverá lavá-los).

Mas Klober Muller, o encarregado da fábrica onde Walser trabalha e seu superior imediato, não parece aprovar a conduta do seu subordinado. Ele censura Walser por causa dos seus "sapatos castanhos absolutamente fora de moda" e afirma que são "sapatos irresponsáveis". A censura aos sapatos sujos de Walser pode ser lida como uma censura à sua conduta diante da guerra. Também pela retórica assumida pela personagem, há em sua fala uma possível alusão ao nazismo, já que a higiene, como elemento identitário distintivo, era ponto importante do programa ideológico nacional-socialista. Diz Klober:

Mas vou explicar-lhe o possível, Walser. Aproxima-se um mês imundo, como dizem as notícias, e o meu amigo tem os sapatos sujos e gastos, entende? Deve limpá-los imediatamente. Receberemos a imundície com a higiene, entende, caro Joseph Walser? 
Cada vez é mais necessária a ordem. Escandaliza-me que ainda não o tenha percebido.

A loucura organizada aproxima-se e teremos de a receber com 0 rosto neutro. Ninguém respeita os histéricos. A guerra ridiculariza os loucos. A ordem, meu caro. (TAVARES, 2010, p. 14)

A advertência e a censura de Klober propõem a guerra como uma ocasião de exercício de disciplina, a princípio. Mas ao final veremos que, para Klober, essa disciplina está ligada a um individualismo extremo e a um desejo de domínio total sobre os demais. Por sua vez, Joseph Walser, que de início ostenta uma postura desleixada frente à guerra, vai gradualmente se deixando impressionar e seduzir pelo discurso de Klober. A tensão entre os dois homens, no entanto, apenas se acirrará, pois o radical desprendimento que Walser sustenta em relação ao mundo o manterá sempre num certo afastamento em relação a Klober e a seu discurso sedutor em torno da guerra, embora Walser não possa nunca se desvencilhar deles.

O desprendimento de Walser e sua atitude indiferente em relação à guerra se devem, conforme nos é apresentado, à particularidade do seu trabalho com uma máquina perigosa:

Dada a natureza do seu trabalho e da máquina perigosa com que contactava, Joseph Walser não precisava de maior intensidade na vida. A chegada da guerra e a invasão da cidade foram encaradas por ele como acontecimentos quase enfadonhos. A eclosão da guerra foi recebida como se não fosse uma novidade, mas uma repetição. (TAVARES, 2010, p. 23)

Para Joseph Walser, portanto, a guerra se manifesta, antes de tudo, no seu modo de vida cotidiano, no seu ganha-pão, na máquina que ele tem de manter à distância como um inimigo, mas que, por força da lida diária, acaba por considerar também um amigo, numa relação plena de tensão e conflito: “Joseph Walser amava a sua máquina, mas sabia que esta o odiava, a ele, humano, de tal modo que não o largava de vista; a máquina observava-o constantemente, à procura de uma falha, à espera de uma falha" (Tavares, 2010, p. 21).

A relação entre homem e máquina possui um papel primordial, um papel fundador, pode-se dizer, na figuração da guerra aqui presente. Há um convite a se pensar a guerra não simplesmente como função (isto é, resultado) da |36| Revista Eletrônica Literatura e Autoritarismo, no 24 - julho a dezembro de 2014 - ISSN 1679-849X http://cascavel.ufsm.br/revistas/ojs-2.2.2/index.php/LA/index 
máquina, mas igualmente a se pensar a máquina como conformadora de um quadro de relações sociais que dispõe à guerra e a um determinado tipo de guerra: aquela com desdobramentos de dominação total.

Além disso, a tensão e a ligação que se estabelecem entre Joseph Walser e Klober Muller nos indicam a relação, igualmente tensa e incontornável, entre a neutralidade e a indiferença (ou a tentativa delas) e a violência que almeja o domínio total. Aos poucos percebemos que essa indiferença de Walser, bem como a maldade e o individualismo extremo dela resultantes, constituem não uma característica individual, mas são como que o clima geral da cidade. As atitudes de Walser que mais chocam o leitor são, justamente, omissões: o personagem não faz nada para evitar que Fluzst, supostamente seu amigo, seja preso e fuzilado; não tem qualquer escrúpulo em ter um caso com a viúva de Fluzst, Claire; e, ao mesmo tempo, não reage ao adultério e à infelicidade de sua própria mulher, Margha. Nesse sentido, podemos considerar, paralelamente, aquilo que o narrador discorre a respeito da fase inicial da guerra:

A maldade é uma categoria do raciocínio. Não é uma invenção sobrenatural, nem cresce a partir de substâncias inscritas nos vegetais comestíveis. A maldade é uma categoria do instinto, sim, mas também do raciocínio, da inteligência. Como se fosse uma etapa do percurso que o cérebro matemático faz quando pretende resolver problemas numéricos. Dedução, indução e maldade.

Mas mais distribuída que a maldade está essa indiferença universal que nasce do facto de os corpos estarem violentamente separados mesmo em tempos de calma. As matérias são incompatíveis e certas repetições de nome tentam mascarar o evidente: nenhuma matéria tem nome igual. Grande parte da cidade foi conquistada por esse exército neutro que não é exército: a indiferença. Se queres sobreviver colocas a tua coragem num saco plástico e aguardas. (TAVARES, 2010, p. 36)

Percebe-se, assim, que no universo desta narrativa a indiferença em meio à situação da guerra é retratada como uma espécie de estratégia de sobrevivência, da qual o personagem Walser seria o representante exemplar. "Não há fórmulas para a indiferença, pois há diversas maneiras de sobreviver e a neutralidade é uma delas" (Tavares, 2010, p. 38). A indiferença, nesse sentido, parece ser a regra geral, e não há fórmulas para exercê-la, pois o que 
importa acima de tudo é garantir a sobrevivência individual e cada um dará conta disso de um modo pessoal. Walser o fará através da neutralidade radical, o que, ao final, se revelará insustentável. Insustentável porque é justamente essa neutralidade radical que fará de Joseph Walser uma espécie de cobaia das teorias de Klober Muller, o seu superior na fábrica. O "afecto" que Klober diz sentir por Walser parece ser uma forma de o colocar constantemente em teste. Como se o encarregado realizasse um experimento a fim de definir o que é um "grande Homem". Klober tem a sua teoria de que um grande homem é aquele que sabe sustentar uma "explicação individual" para as coisas e que resiste à realidade coletiva - que para ele se configura na moral e na História através do ódio:

Só há um verdadeiro ser não coletivo, não social, como se diz por aí. E esse ser não é o que se isola, não é o que foge para a montanha ou para a floresta, esse ser é o que mata os outros, o que quer matar todos os outros para finalmente ficar sozinho, esse é o verdadeiro ser solitário. (...) É o ódio a grande marca do Homem, da sua particularidade própria, da sua exibição da diferença, da sua separação em relação às outras coisas. É o ódio que te dá o nome. (TAVARES, 2010, p. 119)

Para Klober, a guerra é um momento privilegiado para que a "verdade do Homem" venha à tona, a qual, na sua visão, consiste no fato de que o verdadeiro indivíduo odeia e quer destruir todos os outros. Contudo, segundo Klober, a guerra que há de expor a "verdade final do homem" ainda estaria por vir, e "será aquela em que cada um combaterá todos os outros, em que cada homem será o início e o fim do seu exército" (Tavares, 2010, p. 120).

A princípio impressionado com Klober e com o tipo de considerações que ele ousa fazer em público, Walser pensa em si mesmo como alguém que evidentemente não era e nunca seria um "grande Homem". E o fato de Klober dormir com a mulher de Joseph Walser e ainda admiti-lo sem qualquer incômodo parece aprofundar ainda mais a distância entre o encarregado, sujeito que deseja ser um grande Homem, e o empregado Walser, que não possui qualquer desejo nesse sentido. Contudo, é justamente ao pesar a distância entre si e o seu superior que Walser chega à conclusão de que, dentro da própria lógica de Klober, ele, Walser, é quem na verdade estaria do lado mais forte. Pois enquanto Klober Muller ainda deseja a admiração dos 
outros, Joseph Walser não sente nenhum tipo de ligação em relação aos demais - e é por isso que não quer, por sua vez, ser um grande Homem. Tal coisa o deixa com a impressão de haver superado Klober, não obstante a grandiloquência e as formulações ousadas deste. Lê-se no romance:

Em suma, havia nele, Walser, afinal, um ódio generalizado, um ódio sereno mas geral, um ódio dirigido a todos e a cada um dos indivíduos com quem a sua existência se cruzava.

(...) Ainda não era o verdadeiro Homem, como dizia Klober, o Homem que quando se aproxima se aproxima para matar; mas havia já nele algo de muito significativo: qualquer aproximação a outra existência, não sendo ainda para a eliminar, era já, e desde há muito, para não amar. (...) Já estou preparado para não amar ninguém - e esta frase dita assim, para si próprio, era sentida como a sua grande arma em tempo de guerra, a grande defesa em relação à agressividade do século. Não tinha sequer uma pistola, mas eliminara a grande fraqueza da existência, fizera desaparecer a primária fragilidade da espécie: não possuía qualquer inclinação para o amor ou para a amizade! (TAVARES, 2010, p. 129)

Mas "a sua grande arma em tempo de guerra", a arma da indiferença radical, não será, afinal, eficaz para enfrentar o encarregado Klober. Pois o jogo letal - uma espécie de roleta russa combinada com o jogo de dados - no qual Klober obriga Walser a tomar parte não deixa espaço para a indiferença. Daí a nossa leitura de que a figuração da guerra nessa narrativa põe em questão a associação que se oportuniza entre a indiferença radical e a expansão do ódio totalitário, motor da guerra total. A indiferença conduz ao isolamento e impossibilita a sustentação de relações sociais saudáveis. É esse tipo de conformação social, que se caracteriza por uma massa de indivíduos atomizados - isto é, isolados uns dos outros, embora compartilhando a mesma estrutura político-burocrática - que Hannah Arendt, por exemplo, identificou na gênese dos movimentos totalitários, em sua obra de referência sobre o tema, Origens do Totalitarismo ${ }^{5}$.

\footnotetext{
${ }^{5}$ Diz Arendt, na obra mencionada: "Potencialmente, as massas existem em qualquer país e constituem a maioria das pessoas neutras e politicamente indiferentes, que nunca se filiam a um partido e raramente exercem o poder de voto. Em sua ascensão, tanto o movimento nazista da Alemanha quanto os movimentos comunistas da Europa depois de 1930 recrutaram os seus membros dentre essa massa de pessoas aparentemente indiferentes, que todos os outros partidos haviam abandonado por lhes parecerem demasiado apáticas ou estúpidas para lhes merecerem atenção". Arendt, 1989, p. 361-362.
} 
Em um ensaio escrito por ocasião do cinquentenário do livro de Hannah Arendt Eichmann em Jerusalém ${ }^{6}$, a pesquisadora francesa Claudine Haroche, ao caracterizar a "personalidade totalitária", perfil individual que foi moldado e privilegiado pelo contexto nazista, faz as seguintes considerações, que nos parecem muito pertinentes para se analisar o personagem Joseph Walser e os desdobramentos da sua postura:

Arendt insistirá muito sobre o fato de que no totalitarismo o fator inquietante era o "autêntico desinteresse de seus partidários" pelo mundo, pelos outros. A principal característica do homem de massa "não é a brutalidade ou o retardo mental, mas o isolamento e a falta de relações sociais normais" que o levam então à organização. Arendt observa que é a "identificação com o movimento e o conformismo absoluto (que) parecem ter destruído até sua capacidade de viver uma experiência mesmo no caso da tortura ou do medo da morte". (HAROCHE, 2013, p. 108)

A indiferença de Walser, no limite, também o impede de escapar da própria morte. Essa indiferença, portanto, destrói a sua própria experiência como indivíduo, uma vez que o impossibilita de reagir em defesa da própria vida. Essa amputação da personalidade de Walser, essa incapacidade de se pôr em relação com os demais, está simbolizada, parece-nos, pela amputação do seu dedo indicador direito, causada por um acidente de trabalho com sua perigosa máquina. A falta desse dedo, que incomoda sua amante Clairie e atiça, simultaneamente, a repulsa e a atração de Klober, é o que, em última instância, impede Walser de agir em favor de sua própria vida no jogo letal que Klober the propõe, deixando-o totalmente à mercê deste. Pois o dedo que the falta é o dedo que dispara o gatilho, "o dedo essencial para matar", indispensável, na lógica de Klober, para que um homem se coloque no lado forte da existência.

Em síntese, a relação entre Walser e Klober - na qual tem um peso importante o final em aberto, em que não sabemos quem há de receber a bala do revólver de Klober, embora o cálculo das probabilidades deixe Walser mais próximo disso -, especialmente no que tange ao seu comportamento diante da

${ }^{6} \mathrm{O}$ ensaio em questão encontra-se publicado numa coletânea recentemente lançada pela Editora da UFPR: BREPOHL, Marion (Org.). Eichmann em Jerusalém: 50 anos depois. Curitiba: Editora UFPR, 2013. Os ensaios dessa coletânea se dedicam à reflexão tanto a respeito do julgamento de Eichmann, em si, quanto do livro de Hannah Arendt que desse acontecimento resultou.

|40| Revista Eletrônica Literatura e Autoritarismo, o 24 - julho a dezembro de 2014 - ISSN 1679-849X http://cascavel.ufsm.br/revistas/ojs-2.2.2/index.php/LA/index 
guerra, iconiza, segundo nossa leitura, o processo de retroalimentação que se desenvolveu entre 0 isolamento dos indivíduos e a ascensão de regimes totalitários.

Além disso, a teoria de Klober Muller de que um "grande Homem" é aquele que se coloca acima da História e da moral, fazendo a sua existência individual predominar sobre a existência coletiva por meio do ódio dirigido a todos, é algo determinante para o rumo da narrativa e algo que pode, ainda, ser posto em paralelo com aquilo que Theodor Adorno chamou de "personalidade autoritária", conceito em vários pontos similar ao da "personalidade totalitária" de Haroche. No ensaio "The authoritarian personality" (1986), um misto de análise sociológica e psicológica, Adorno descreve o papel da "personalidade autoritária" na ascensão e constituição do regime totalitário nazista. Caracteriza esse perfil psicológico e moral (um perfil também político, portanto) como dotado de um "caráter manipulativo", o qual se manifesta especialmente pela disposição de tratar os demais como massa amorfa e se distingue "pela mania de organização, pela incapacidade de vivenciar experiências humanas em geral, por certa espécie de falta de emotividade, pelo realismo exagerado" (Adorno, 1986, p. 40). O caráter manipulativo é um "tipo com consciente coisificado", um "consciente que rejeita tudo que é consequência, todo o conhecimento do próprio condicionamento, e aceita incondicionalmente o que está dado" (Adorno, 1986, p. 40).

Parece haver várias notas em comum com a personalidade tanto de Klober, que através do ódio generalizado procura ser um "grande Homem", quanto do próprio Walser, que não deseja ser um "grande Homem", mas que, através da indiferença generalizada, atinge o mesmo grau de isolamento que Klober preconiza em suas teorias. (Diga-se, ainda, que a personalidade autoritária também encontra ressonâncias no personagem real Adolf Eichmann.) Tal coisa, essa espécie de encontro entre Klober e Walser, está em consonância com a nossa análise, anteriormente exposta, de que os dois personagens se aliam na constituição de um cenário de guerra total: a indiferença, decorrente do atrofiamento da consciência e da capacidade de julgar, é a contraface da violência exercida em moldes totalitários. É apenas essa indiferença radical, estabelecida em larga escala na sociedade, que 
possibilita o exercício institucional dessa forma de violência também radical: o extermínio.

\section{REFERÊNCIAS}

ADORNO, Theodor. Educação após Auschwitz, pp. 33-45. In: Sociologia. Gabriel Cohn (org.) São Paulo: Ática, 1986.

ARENDT, Hannah. Origens do totalitarismo, Trad. de Roberto Raposo. São Paulo: Companhia das Letras, 1989.

FILHO, Antonio Gonçalves. Jerusalém e a presença do mal. O Estado de $S$. Paulo. São Paulo, 17 de setembro de 2006, Caderno Cultura, p. D11.

HAROCHE, Claudine. Crueldade da personalidade totalitária, crueldade da personalidade ilimitada, pp. 103-124. In: BREPOHL, Marion (Org.). Eichmann em Jerusalém: 50 anos depois. Curitiba: Editora UFPR, 2013.

TAVARES, Gonçalo M. Um homem: Klaus Klump. São Paulo: Companhia das Letras, 2007.

. A máquina de Joseph Walser. São Paulo: Companhia das Letras, 2010. 